\title{
THE NORWEGIAN COMPUTING CENTER AND THE UNIVAC 1107 (1963-1970)
}

\author{
Knut Elgsaas and Håvard Hegna \\ 1. Elgsaas, Researcher/Project Director (1963-73), Norwegian Computing Center, \\ elgsaas@c2i.net \\ 2. Hegna, Senior Researcher (1962-), Norwegian Computing Center, havard.hegna@nr.no
}

\begin{abstract}
The Univac 1107 computer installation at The Norwegian Computing Center (NR) from the summer of 1963 was an important asset for Scandinavian research and industry that also set the ground for object-oriented programming. The key to many of the successful computer systems and applications created during the years that followed, was that NR at a very early moment in the history of modern computing, managed to acquire the most suitable computer for these developments and establish a fruitful user community around it. The unwinding of the installation during 1969/70 led to a strong conflict that began as an internal dispute between the employees of NR and its managing director, and ended as an open struggle between NR and the Royal Norwegian Council for Scientific and Industrial Research (NTNF) and to subsequent changes in the research organization of Norway.
\end{abstract}

Key words: Central computers, research policy, Simula 67, Univac 1107

\section{THE UNIVAC 1107 INSTALLATION AND ITS USE}

\subsection{Introduction}

The Norwegian Computing Center (Norsk Regnesentral, NR), a research institute subordinate to the Royal Norwegian Council for Technical and Industrial Research (NTNF), signed contracts with Remington Rand Univac in 1962/63 that had several important consequences. First, Remington Rand delivered a Univac 1107 computer to NR in August 1963. This delivery 
gave NR and Norway the largest non-military computer installation in Europe at the time. Secondly, NR was to develop a linear programming package [1] and a simulation language with a corresponding compiler for the Univac computer. The language, Simula I, was the precursor of the Simula 67 language $[2,3]$ that introduced the concept of object-oriented programming and gave its two inventors Ole-Johan Dahl and Kristen Nygaard the IEEE von Neumann Medal and the ACM Turing Prize 35 years later. However, most important was the intensely creative and productive environment for the development of computer applications, quantitative methods, and computer science research that followed the installation. The principal driving force behind the Univac deal was Kristen Nygaard, Research Director at NR 1960 - 1984.

\subsection{Not an easy decision}

There were several obstacles to the procurement of the Univac 1107. NR had already signed contracts in 1961 for the delivery of a GIER computer from Danish Regnecentralen (DR) in the spring of 1962. GIER was a wonderful well-constructed middle-sized computer with a good Algol 60 compiler. The compiler was a primary reason for the choice of GIER. Important were also the visions of DR's chief executive, Niels Ivar Bech, for a grand Scandinavian cooperative effort in computer research, education, and industry. DR installed a GIER at the Norwegian Technical University (NTH) in Trondheim in November 1962 [4]. It was part of a double contract where a second GIER should go to NR. The NR decision to go for the Univac solution instead led to Danish-Norwegian intriguing and an internal conflict in NR that ended with the dismissal of several of its employees.

In 1962, the prevalent thinking still distinguished between computers for scientific or for administrative tasks. The Univac 1107 was the first commercial computer to bridge that gap. Nevertheless, it was not obvious that such a tool should come to NR. NR's strongest rival was the Norwegian Defense Research Establishment (FFI) [5]. The leader of FFI lobbied hard for his organization both in NTNF, he was a member of NTNF's working committee, and in the Ministry of Defense, seeing clearly that Norway at the time could not afford, or find use for, two such machines.

In many ways NR was a perfect institution for the double-purpose Univac 1107, being open to research and business both through necessity and by virtue. NR bought the computer through a loan from NTNF that required payments over eight years. NR therefore had to open itself up and act as a service bureau to any interested customer. In all probability, a grant to FFI would instead have placed the computer resources behind military fences, thus keeping it away from most industrial and public use. NR's marketing effort included the design of a logo signifying its dual 
engagement in digital computing and mathematical-statistical disciplines. Figure 1 is a mosaic rendering of the logo.

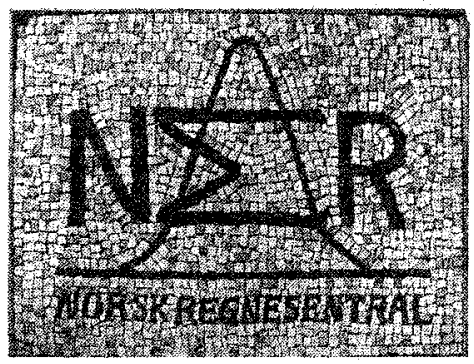

Figure 1: NR's Early Logo

\subsection{The machine and some problems}

The Univac 1107 that was delivered to NR, included $32 \mathrm{~K}$ 36-bit words of ferrite memory, $1572 \mathrm{~K}$ words of secondary storage on two magnetic drums, 6 magnetic tape stations, a punch card reader $(600 \mathrm{cards} / \mathrm{min})$, a line printer (900 lines/min), and a central processing unit with a 4 microseconds instruction cycle. In 1963, it cost 7 million NOK, even at a 50\% discount, which today amounts to about 70 million NOK.

This huge and resourceful machine also brought problems. For one thing, NR, even Norway, had very few computer experts in 1963. Remedial actions were necessary. In October 1962, shortly before the final signing of the contract, NR started a one-year intensive course in computer programming and system development. The both theoretical and practical curriculum covered programming languages, algorithms, software engineering, and methods from operations research, statistics, and numeric analysis. One student, a NTH graduate, later said that this year gave him a larger learning return per time-unit than any other education he had followed. Nevertheless, one set of students was far from enough. NR also set out to brain drain Great Britain. A large group of British programmers and computer specialists took the challenge and NR employed them. A side effect was that English rugby was introduced to NR and Oslo, a team was established that later formed the base for the Norwegian Rugby Union [7].

\subsection{Putting it to use}

NR and its customers used the computer facilities over a wide area of applications. During the Univac years, NR developed Optima (a system for network planning and control of engineering projects $[8,9]$ ), DATSY (a 
special purpose language and system for describing data and establish economic planning models such as MODIS [10]), and program libraries of routines for statistical and numerical calculations,

VEIVALG (a very advanced tool for city transport planning [10]), PADLP (a linear programming package based on a new non-simplex method discovered at NR [1]), numerous administrative data processing systems, and a wealth of computer simulation models for studies of systems at home and abroad [11]. In addition, of course, it contained the Simula language activities that included exports of ideas and products on a global scale. Among the customers were Norsk Hydro (an international producer of fertilizers and aluminum), Staal Laval of Sweden (a dominant dairy equipment manufacturer), Burmeister \& Wain (the largest shipyard of Denmark), Det norske Veritas (DnV) (the Norwegian ship classifier), Akergruppen (a large group of Norwegian shipyards), Kongsberg Weapon Manufacturer, Central Bureau of Statistics, Oslo City Transport Planning, universities, and research institutes. Of particular importance were Autokon (a system for computer aided design and construction of ships developed at the Central Institute for Industrial Research (SI) [12]) and SESAM (a finite element method based structural analysis system developed at NTH and DnV [13]). The work on Autokon and SESAM had started before the arrival of the Univac 1107; they boosted it by the new computer and particularly by the response times made possible by the advanced new drum storage. As early as in 1964, NR together with the Norwegian Teleadministration (Televerket) was able to demonstrate data transmission over the public telephone network. Later that year four distant customers in Sweden, Germany, and two sites in Norway, could communicate over modem and phone to NR simultaneously. NTH, which replaced their GIER computer with a Univac 1107 in May 1965, started their Univac use in 1964 with the installation of a Univac 1004 that communicated with NR [6, 14]. Figure 2 shows some of the important developments that spun from NR and its customers in the sixties and early seventies.

\subsection{A success story}

Univac wanted NR to be one of their main show windows in Europe. They may not have succeeded in the rest of Europe, but their success in Norway was considerable. Two of the three Norwegian universities at the time, acquired Univac computers, as did several of NR's large customers (Norsk Hydro, Veritas, the Norwegian Teleadministration). Oslo University went for a CDC 3300 [15], but the University was for several years a very strong user of NR facilities. It was too strong, in fact, since the sometimesinflexible pricing policy of NTNF and NR was too heavy burden on the 
University. A payment of more than one million NOK had to be remitted in 1966 after long negotiations. Later, the Institute of Informatics (Ifi) at the University was in many ways born out of the activities and educational efforts of NR. Most of the central personnel of the institute, which the University did not formally establish until 1977, had been part of NR for some time [16]. Ole-Johan Dahl became the first professor of informatics at the University in 1968.

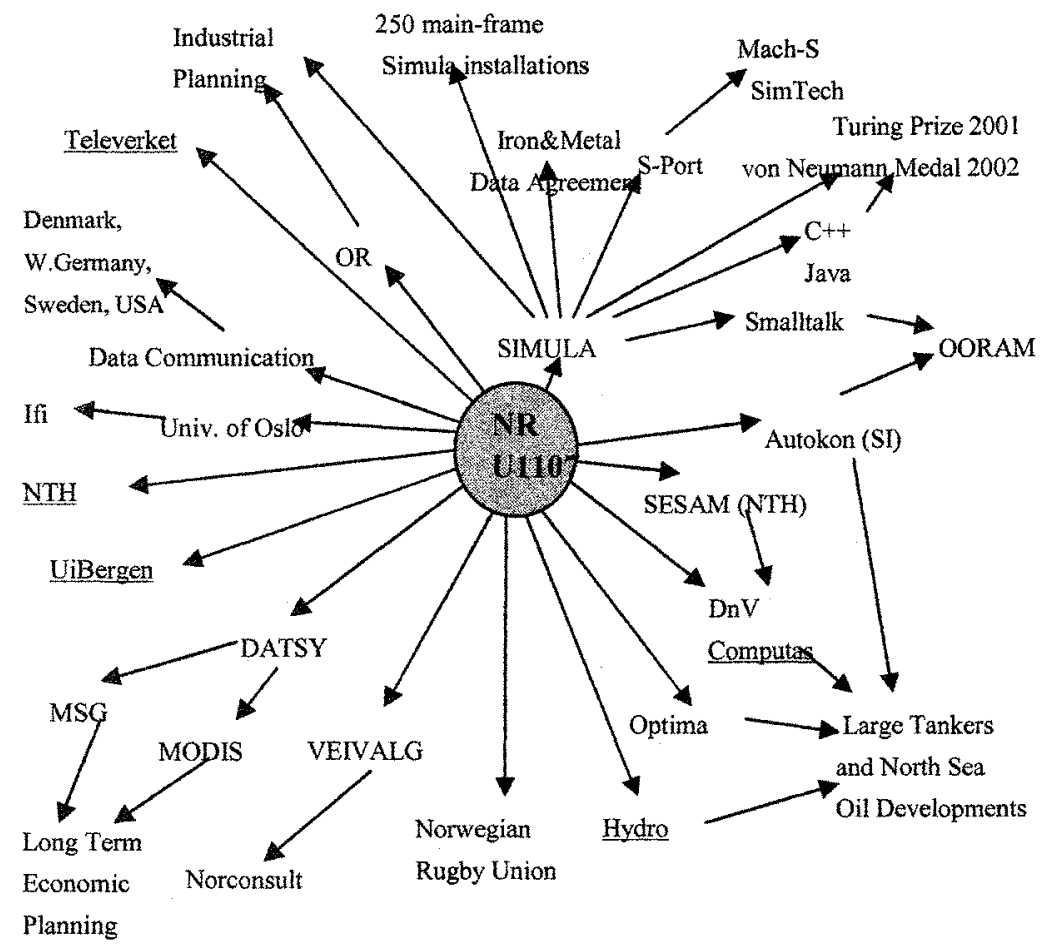

Figure 2: The NR Univac 1107 was at the center of many developments.

(Underlined items refer to large Univac installations in Norway.)

The NR Univac 1107 installation and activities surrounding it in the period 1963-70 were very important for Norwegian industry. The systems that were developed from the beginning of the 1960s, in particular in Akergruppen and Veritas, were a necessary condition for the construction of large oil tankers (the size grew from 30000 tons to over 400000 tons in a very short time) as well as for semi-sub oilrigs, spherical gas-tankers, and oil platforms, indeed for the complete technical development of the maritime 
industry during that period. These developments would not have been possible without the Univac 1107 and the strong integration of industry users and NR. Norway was at the time ahead of the rest of the world in this area, a time that coincided with the start of North Sea oil activities [13].

\subsection{An important resource}

For NR, the Univac 1107 was a valuable computer resource and source of income at the end of the 1960s. It contributed a yearly net income of about 1.2 million NOK of a total NR turnover of 8-9 million NOK. NR had no problems with settling the loan from NTNF. The income and marginally priced computer power gave important support and freedom to the researchers at the institute. This freedom was a presupposition for the Simula work of Dahl and Nygaard. There was no other available financial support for their far-reaching research. According to the research council and other NR surroundings, both in the 1960s and later, there was no need for another language like Simula; it had been done before, the two initiators were not competent enough, such languages were very short-lived, and language development was not a natural task for the smaller countries [2]. Hardware was considered a more important research theme. It is ironic that the Simula achievements later led to advanced hardware design work and the Mach-S of SimTech/Sim-X that had a Simula-based instruction set and object-oriented addressing [25].

After Computas took over the Univac 1107 in 1970, the developments that started at the NR site advanced further, leading to successful use in application areas such as seismic activities, oilrig construction, engineering control, and building industry. The key to all this was that NR at a very early stage in the history of modern computing managed to acquire the most suitable computer for these developments and establish a fruitful user community around it.

NR had four leaders during the Univac 1107 years. They were Siv. ing. Leif K. Olaussen (1963-66), Cand act. Herdis Thorén Amundsen (1966-67), Siv. oecon. Lars O. Sødahl (1968-69), and Cand. mag. Drude Berntsen (1969-90). In view of the high-tech profile of the institute in this period, and male dominance in computer industry as a whole [17], it is amazing that two of the four leaders of NR at the time were women. 


\section{CRISIS AND CONFLICT 1969-70}

\subsection{Background}

During 1969/70 the Norwegian Computing Center (NR) went through a crisis and conflict that reached a magnitude and gave it a public exposure that probably no other Norwegian research institution has ever experienced $[18,19]$. The sale of NR's computer Univac 1107 precipitated the conflict. It began as an internal dispute between the employees of NR and its managing director, and ended as an open struggle between NR and the Royal Norwegian Council for Scientific and Industrial Research (NTNF). NR was then a research institute subordinate to NTNF.

Shortly after Univac 1107 became operational in 1963, at that time it was one of the most powerful computers in Europe, NR had many customers from other institutes, the University of Oslo, public agencies, and private business. As mentioned earlier, the operation of Univac 1107 was a scientific and economic success. The computer generated a net profit that made it possible to finance research activities at NR such as the development of the Simula language and compilers.

The market noticed the success of Univac 1107. In 1968, a new company, Computas, a subsidiary of Veritas, planned to acquire a Univac 1108. Computas offered services to its mother organization as well as to other customers of NR at substantially lower prices than the NR level. The director of NR feared the economic problems the Computas competition would create. He therefore proposed to the NR board that they should sell the Univac 1107 with its customers to Computas.

\subsection{Start of the conflict}

The employees of NR did not know about the sale until after NTNF had received the proposal from the NR board. A majority of the employees were critical of the secret handling of the case. The scientific personnel were also strongly irritated by not being consulted about such a vital matter for NR. The criticism exacerbated when an internal investigation a couple of months later proved that the sales contract between NTNF and Computas was very disadvantageous to NR and NTNF, and even to Computas.

The investigation made it clear that research and development based on the use of computer-time at a marginal cost no longer would be possible. In the future NR therefore would not be able to develop software products like SIMULA or OPTIMA. The operation of Univac 1107 had contributed to a close contact with many public and private organizations and companies. This in turn led to a number of jobs for NR not connected to programming or 
use of the computer. The staff at NR feared that the sale of the 1107 would reduce the possibilities of such contacts.

The growing criticism caused the establishment of the Union of Employees at NR (FANR) in March 1969. NTNF, in an attempt to answer the criticism from NR, in a letter to FANR in May 1969 stated that they made the decision to sell Univac 1107 with special consideration for the future activities at NR.

The dissatisfaction with the way they handled the sale, led to a vote of no confidence against the director at a FANR meeting in June. Consequently, the director was unable to function as leader of NR. The board of FANR, therefore, advised the board of the NR to engage Drude Berntsen, an NR female employee, as a de facto managing director. During the spring of 1969, an open and good relationship developed between the two boards. The board of the NR acted upon the advice from FANR and appointed Drude Berntsen as deputy director of NR in August. At the same meeting, the board approved a plan for future activities for NR and submitted the plan to NTNF. Berntsen remained in office until 1990.

Robert Major, the managing director of NTNF, did not like the developments at NR. The establishment of a rather militant union was unheard of in the research institutes belonging to NTNF. His displeasure with NR did not decrease when the director, a man handpicked by NTNF to lead NR, was forced to leave.

In October 1969, the chair of the board of NR, Odd Narud (the later General Director of Norsk Hydro) asked for a meeting with Robert Major. He raised the question of appointing a new director of NR. Major stated that they should not announce the position as director until NTNF considered the plan for the future activities for NR. Narud said that the board of NR and the employees felt that the handling of the plan seemed to take too long. Major then informed Narud that he had appointed a 3-man committee to examine the plan. The secretary of the committee was the deputy director of NTNF.

\subsection{The report from the three-man committee}

On 3 December 1969, the committee presented their report on the plan for NR [20]. The report described the development in data processing and the use of quantitative methods in Norway. The committee members were of the opinion that the data profession in Norway had reached such a high level, quantitative and qualitative, that there was no longer any use for a method-oriented institute like NR. The committee therefore proposed that they should transfer the professional activities at NR to four growth-centers: 
- Statistical methods and analysis together with language development to the University of Oslo.

- Research and analysis for the public sector to other institutes belonging to NTNF.

- Work for the building and construction sector to the Institute for Building and Construction (NBI).

- The remainder to the Central Institute for Industrial Research (SI).

The committee's assertion of the high professional level of data competence in Norway was based on a poll made by the secretary. He had called some institutes and firms and asked them how many employees they would describe as qualified systems analysts. The numbers were amazingly high. He had not asked NR of course, but had found out by himself that of 94 employees there were 65 qualified systems analysts. That number was obviously much too high, as was the case with the other institutes and firms. One of the firms, which in the report from the committee was entered with ten systems analysts, declared they had none. The one qualified analyst working for them had quit. In a meeting on 5 December, the secretary admitted the numbers of qualified analysts were somewhat diffuse. When asked for his definition of a qualified systems analyst, he responded: "I would like to turn the question around. How does one define a qualified systems analyst?"

\subsection{Meeting with NTNF}

The report from the three-man committee caused a meeting to take place on 5 December between NTNF, the three-man committee, and the boards of NR and FANR. The report was strongly criticized by members of these boards. At the end of the meeting, the chair of the three-man committee withdrew his support of the report and proposed that they should conclude the meeting with a protocol stating: "We agree on maintaining NR as a method oriented institute on a high [professional] level". The chair of NTNF, the chair of the board of NR, and the chair of the Union of Employees of NR signed a protocol with that statement. A similar protocol had never before been signed in the NTNF-system. It came as a conclusion of a meeting where the chair of NTNF criticized Robert Major and treated the Union of Employees as an equal partner to the boards of NTNF and NR.

Robert Major was not pleased with such a conclusion. A couple of days before Christmas, he was able to get the board of NTNF to approve a drastic reduction of the staff at NR. The reason was the so-called difficult economic situation at NTNF. The board of NR and the board of FANR criticized strongly the proposal from NTNF. The board of NR stated that they could 
not carry out such a reduction in one year; the earliest would be in two years time. The board of FANR stated they would not accept the proposal.

\subsection{The conflict becomes a public issue}

The employees of NR felt that this decision was a breach of the protocol entered earlier and the promise given in May by NTNF. At an extraordinary annual meeting of FANR in the beginning of January 1970, they passed a resolution that demanded the withdrawal of the decision of NTNF. They distributed the resolution to all the major newspapers. The next day and the following weeks the headlines in newspapers all over Norway told the story of a serious conflict between NR and NTNF, see Figure 3 and below:

"NR has lost confidence in NTNF". Aftenposten 13.1.70.

"Complaints over the reductions at computing center". Bergens Tidende 13.1.70.

"Rationalization has created great bitterness at NR". Fadrelandsvennen 13.1.70.

"Unrest at NTNF" Arbeiderbladet 19.1.70.

"The customers of NR regret the reductions". Morgenbladet 21.1.70

"NR to be cut in four. Halvdan Svarte policy"1. Morgenbladet 23.1.70.

"High political battle on research policy". Dagbladet 23.1.70.

"Lack of democracy within NTNF" Arbeiderbladet 28.1.70.

"Bring the cards on the table". Editorial in Arbeiderbladet 30.1.70.

The press coverage of the conflict continued in February:

"What is going on in NTNF?" Arbeiderbladet 11.2.70

"NR holds the knife at NTNF"s throat" Arbeiderbladet 27.2.70

\section{Reguesentralen foreslatt delt i fine: "Halvdan Svarte-politikk!"}

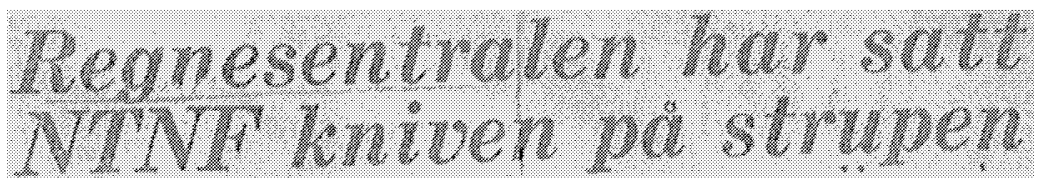

Figure 3: Newspaper headlines 1970, "NR to be cut in four. Halvdan Svarte policy!" and "NR holds the knife at NTNF's throat".

FANR received support from among others, the University, other research institutes, and private business. The conflict caused the leader of

${ }^{1}$ Halvdan Svarte, i.e. "Halvdan the Black", was a famous petty king in Norway in the 9th century A.D. Because of his popularity, when he died his body was cut in four parts that were entombed in grave mounds in the four regions of his kingdom. 
the Norwegian Labour Party in the Storting (Parliament) to put a formal question before the Prime Minister on 20 January [21] about the organization of research in Norway:

"Research is an increasingly important factor in the development of modern society. Is the Government of the opinion that we have a satisfactory organization of research [in Norway], or does the Government have plans for organizational, administrative and economic measures to secure a social use of the results of the possibilities of modern research?"

\subsection{The end of the conflict}

NTNF lost the battle for the public opinion. At a meeting in March, the NTNF council voted unanimously that " $N R$ shall remain a method-oriented institute at a high professional level". FANR had won, and NR is still going strong more than 30 years later.

On 24 March, the council of NTNF in a long article in Aftenposten (the largest and most influential newspaper in Norway) gave their account of the course of events concerning NTNF and NR [23]. The main points were that the staff of NR was unrealistic in their view of the economic future of the institute and that even though the timeframe for decision making about NR was very narrow because of external circumstances, NTNF's decisions were well grounded. On 7 April, the chair of the union of employees of NR, Sverre Spurkland, in an article in the same newspaper documented that the council had misrepresented the facts [24]. He therefore suggested the establishment of a neutral commission with a mandate to collect all written material with relevance to the case. For researchers investigating the decision processes in NTNF such material would be of great value. The council of NTNF did not answer the serious allegations of Spurkland. Nor was a neutral commission established. ${ }^{1}$

The conflict between NR and NTNF appeared to most people to be complicated and difficult to understand. Computers, data processing, and research activities were not common themes in the public debate. What everybody understood, however, was that NTNF had broken its promise in the letter of May 1969. Such a breach of promise was not acceptable, neither in the public opinion nor among politicians.

${ }^{1}$ After submitting the first draft, the authors received the following suggestion from the HiNC programme committee: ".... Try also to write the "conflict" part somewhat more impartially - had NTNF written about the conflict, we are sure the text would be somewhat different." Our description of the conflict has not been altered, but we decided to add the above paragraph. Our description has been based on written documentation, letters, minutes, newspaper articles, official documents, etc., see references. NTNF gave its version of the conflict in the Aftenposten article. NTNF never openly challenged the allegations that its presentation misrepresented the facts. 
What was the conflict all about? First, it did not concern the continued operation of NR as a seller of raw machine time. Early in 1969, the staff at NR estimated the technical-economical working life of Univac 1107 to last a couple of years until 1971/72. They realized that the period as a vendor of raw computer time soon would end. Nevertheless, the staff was of the opinion that if NTNF and the director of NR had sought their advice, NR would have obtained more favorable terms in the contract with Computas and there would have been a more flexible transition to other computers.

The fundamental cause of the conflict was the organization of NTNF. Many characterized the manner in which Robert Major had run NTNF from its beginning in 1946 as a "one-man show". In central government circles, this was pragmatically accepted. They considered Major as an effective "permanent undersecretary of state" for a successful "ministry of research". However, times were changing.

The conflict initiated a process of reorganization of NTNF and its institutes in the 1970s. In NOU 1981: 30B "Investigation of public grants to technical and industrial research and development in Norway" a report from NAVF (Norwegian Research Council for Sciences and Humanities) [22] describes how the conflict influenced the organization and management of NTNF.

"The conflict with NR caused a wide public debate about the organization of research in Norway and more specifically the organization of NTNF.... Both the question about NR and the later public debate served as parts of the background for the decision of NTNF to make an analysis of their organization in the Habberstad-investigation".

The report from NAVF also points out that the conflict with NR caused a demand for co-determination from other groups of employees within the NTNF-system and more openness around the decisions of NTNF. "Such demands were earlier almost unheard of within NTNF".

\subsection{Evaluation of the conflict thirty years later}

The employees at NR and most certainly the management of NTNF experienced the conflict as difficult, frustrating, and unpleasant. The conflict was one that they would have liked to avoid. Viewed in retrospect, however, the chair of the board of FANR, Sverre Spurkland, probably was right in saying that the conflict benefited both NTNF and research in Norway. It brought to the light problems and circumstances in NTNF, which later might have caused more trouble than the conflict in 1969-70. The conflict contributed to a greater interest for research and development both among politicians in the Storting and in the public as well. The NTNF also learned a lesson. Later they avoided making the same serious mistakes in relations to their institutes as they did in the case of NR. 
The conflict was also beneficial for NR. It forced a thorough analysis of the future tasks of the institute. The conflict strengthened the team spirit between the employees in the difficult process of transition to a situation without a large computer and cheap computer-time. The employees of NR also had the pleasant experience that the victory over NTNF won against all odds, actually strengthened the reputation of NR in the market. That experience contributed significantly to the self-confidence a research institute needs when it goes through an extensive reorganization.

\section{REFERENCES}

[1] Spurkland, S.: The Parametric Descent Method of Linear Programming; Norsk Regnesentral 1963

[2] Dahl, O.-J. and Nygaard, K.: The Development of the Simula Languages; in Wexelblat, R.L. (ed): History of Programming Languages; New York: Academic Press 1981

[3] Holmevik, J.R.: Historien om Simula; in NR 1952-2002', p. 109-128; Oslo 2002

[4] Stenstadvold, K.: Elektronisk regnemaskin ved NTH; Teknisk Ukeblad, 25 October 1962

[5] Holmevik, J.R.: Educating the Machine; Centre for Technology and Society, Report 22; Trondheim 1994

[6] Olaussen, L.K.: Midt på 1960-tallet; in NR 1952-2002, p. 33-45; Oslo 2002

[7] Edwards, D.L1.: Hvordan startet rugby i Norge?; in NR 1952-2002, p. 351-354; Oslo 2002

[8] Heier, K.M.: Optima; in NR 1952-2002, p. 191-199; Oslo 2002

[9] Sanders, N.: Project Planning in Norway; Project Manager Today, Great Britain; July 1998

[10] Elgsaas, K. and Hegna, H.: Samfunnsplanlegging; in NR 1952-2002, p. 183-190; Oslo 2002

[11] Hegna, H.; Lund O.J., and Nygaard, K.: User's Experience with the Simula language; Norsk Regnesentral, Oslo, June 1968

[12] Reenskaug, T.: Applications and Technologies for Maritime and Offshore Industries; HiNC- 1 <this conference>

[13] Vahl, T.: Industrial significance of computer applications; HiNC-1 <this conference>

[14] Sanders, N.: Kontakten mellom NR og NTH-SINTEF (1963-1965); in NR 1952-2002, p. 307-308; Oslo 2002

[15] Jacobsen, Per H.: IT-historien@UiO; USIT ved UiO; Oslo oktober 2001 (Beta-versjon)

[16] Dahl, O.-J.: Hilsen fra Ifi ved jubileet i 1998; in NR 1952-2002, p. 346-347; Oslo 2002

[17] Lindencrona, E.: An ICT mystery - where were the women?; HiNC-1 <this conference>

[18] Elgsaas, K.: Krise og konflikt (1968-1970); in NR 1952-2002, p. 309-333; Oslo 2002

[19] Sødahl, L.O.; Min tid på Norsk Regnesentral; in NR 1952-2002, p. 334-338; Oslo 2002

[20] NTNF-document K.318: Om Norsk Regnesentrals fremtidige virksomhet (Report on the future activities of Norsk Regnesentral from the 3-man committee appointed by NTNF); (Håkon Sandvold, chair, Erik Brandt Olimb, Tor Evjen, secretary); Oslo December 1969

[21] Stortingstidende (Records of the Norwegian Parliament) 1970, p. 2334-2355

${ }^{1}$ Norsk Regnesentral 1952-2002 (The History of the Norwegian Computing Center 19522002); Norsk Regnesentral, Oslo, September 2002 (in Norwegian) 
[22] Collett, J.P. and Skoie H.: Teknisk-industriell forskningsorganisasjon i Norge 1945-80. Prinsipiell debatt og hovedlinjer i utviklingen; Vedlegg 3 til NOU 1981 30B, Utredning om offentlig støtte til teknisk industriell forskning og utvikling i Norge (Thulin-utvalget); NAVF-utredningsinstitutt Oslo 1981.

[23] NTNF: Om Norsk Regnesentral. Article in Aftenposten, 24 March 1970.

[24] Spurkland, Sverre: Norsk Regnesentral og NTNF. Article in Aftenposten, 7 April 1970.

[25] Syrrist, G. and Piene, J.: SIMULA-historien etter 1980; in NR 1952-2002, p. 134-138; Oslo 2002. 